\section{Treatment of hypertension in the UK: simple as ABCD?}

The measurement of blood pressure in primary care is a simple screening test to identify individuals at high risk of cardiovascular disease, including stroke. Hypertension is one of the most important preventable causes of premature morbidity and mortality ${ }^{1}$ and a recent analysis of combined epidemiological data indicates that the relation between blood pressure and cardiovascular disease is much steeper than previously thought $;^{2}$ in other words, the potential benefits of intervention are higher. Allied to these impressive population data is a clinical-trials evidence base larger than any other in clinical medicine, pointing to the effectiveness of antihypertensive therapy in reducing cardiovascular risk. ${ }^{3}$ This evidence has provided the substrate for numerous guidelines on detection and treatment. The Chief Medical Officer for England has identified hypertension as one of his five priority areas, and the treatment of hypertension is a key target in National Service Frameworks for the prevention of coronary heart disease and stroke.

Although there are claims for drug-specific benefits, the effectiveness of antihypertensive therapy is most powerfully determined by the reduction in blood pressure achieved on treatment -i.e. by the quality of blood pressure control. 2,3 Yet, according to the Health Survey for England, the proportion of hypertensive patients who in 1998 achieved a blood pressure goal of $<140 / 90 \mathrm{mmHg}$ was only some $10 \% .^{4}$ The annual impact of this shortfall in treatment has been calculated by $\mathrm{He}$ and MacGregor ${ }^{5}$ as about 62000 unnecessary deaths and 125000 cardiovascular events that could have been prevented.

The study by Professor Walley and his colleagues reported in this issue (p. 525) ${ }^{6}$ is the largest retrospective survey of hypertension treatment yet conducted in the UK, involving over 20000 patients treated in primary care. The findings are disturbing. After a minimum 4 years of followup, only $14 \%$ of patients on treatment had achieved the recommended blood pressure target. We might console ourselves with the hope that, since the patients began treatment in the mid-1990s, things will surely be much better today - but they are not. Importantly, the study provides insight into a key reason why blood pressure is so poorly controlled in UK patients - namely, the high rate of monotherapy. Over $65 \%$ of people with moderate to severe hypertension were treated with a single blood-pressurelowering drug, whereas clinical trials have consistently demonstrated that the typical patient requires more than one drug to achieve good-quality control. ${ }^{7}$ The earlier Health Survey for England ${ }^{4}$ made a very similar observation: only one-third of patients treated for hypertension received more than one drug and less than $10 \%$ received more than two drugs. The 'real world' management of hypertension in the UK seems hard to defend when we consider the potential effectiveness of treatment.

What can be done to improve matters? If more than one drug is necessary to control blood pressure, then guidelines should offer specific advice on which drug combinations are likely to be complementary. In response, the British Hypertension Society (BHS) launched its ABCD algorithm, to provide more didactic advice on the sequencing of drugs. 8 This algorithm is based on simple principles. The first is that younger people ( $<55$ years) generally respond better to drugs that block the renin system - these include 'A' drugs (angiotensin converting-enzyme inhibitors or angiotensin receptor blockers) and ' $\mathrm{B}$ ' drugs ( $\beta$-blockers). In contrast, older people ( $>55$ years) and black people respond better initially to ' $\mathrm{C}$ ' drugs (calcium channel blockers) or 'D' drugs (diuretics). Second, for the majority who will require more than one drug, the logical strategy is to combine $\mathrm{A}$ or $\mathrm{B}$ with $\mathrm{C}$ or $\mathrm{D}$; it is not logical at step 2 to combine $\mathrm{A}$ with $\mathrm{B}$ or $\mathrm{C}$ with $\mathrm{D}$. The third step would involve triple therapy with either $\mathrm{A}+\mathrm{C}+\mathrm{D}$ or $\mathrm{B}+\mathrm{C}+\mathrm{D}$. Where possible and when there is no cost disadvantage, at step 2 fixed-dose combinations would be appropriate to reduce the number of medications. This algorithm approach replicates the process adopted in clinical trials, which invariably achieve better blood-pressure control than realworld clinical practice. Whilst providing a template for rational prescribing it is not restrictive, in that it offers choice within a structured framework. Finally, the patient can be offered an individual treatment plan that sets out the objectives and the strategy required to reduce his or her blood pressure.

What is clear is that improvement on the very poor figures for blood-pressure control in the UK will not come from a new drug but rather from a sharper focus on implementation and process. To some in the medical 
profession, algorithms such as ABCD may seem simplistic and an affront to clinical freedom. I would ask, freedom to do what? - not enough, apparently. This aspect of public health strategy has been failing for too long and is too important to be left to chance.

\section{Bryan Williams}

Department of Cardiovascular Sciences, Clinical Sciences Building, PO Box 65, Leicester Royal Infirmary, Leicester

LE2 7LX, UK

E-mail: Bw17@le.ac.uk

\section{REFERENCES}

1 Ezzati M, Lopez AD, Rodgers A, Vander Hoorn S, Murray CJ; Comparative Risk Assessment Collaborating Group. Selected major risk factors and global and regional burden of disease. Lancet 2002; 360:1347-60
2 Prospective Studies Collaboration. Age-specific relevance of usual blood pressure to vascular mortality: a meta-analysis of individual data for one million adults in 61 prospective studies. Lancet 2002;360:1903-13

3 Collaboration Blood Pressure Lowering Treatment Trialists. Effects of angiotensin converting enzyme inhibitors, calcium antagonists and other blood pressure lowering drugs on mortality and major cardiovascular morbidity. Lancet 2000;356:1955-64

4 Primatesta P, Brookes M, Poulter NR. Improved hypertension management and control: results from the health survey for England 1998. Hypertension 2001;38:827-32

5 He FJ, MacGregor GA. Cost of poor blood pressure control in the UK: 62,000 unnecessary deaths per year. J Hum Hypertension 2003;17:455-7

6 Walley T, Duggan AK, Haycox AR, Niziol CJ. Treatment for newly diagnosed hypertension: patterns of prescribing and antihypertensive effectiveness in the UK. $J R$ Soc Med 2003;96:525-31

7 Williams B. Treating hypertension: it is not how you start but where you end that matters. J Hypertension 2003;21:211-13

8. Brown MJ, Cruickshank JK, Dominiczak AF, MacGregor G, Poulter NR, Russell GI, Thom S, Williams B. Better blood pressure control: how to combine drugs. J Hum Hypertension 2003;17;81-6.

\section{Vocational rehabilitation}

An all-too common effect of sickness or disability is exclusion from the world of work, and thus from ordinary society. To counter it, an approach now favoured by disability rights groups, ${ }^{1}$ the Government ${ }^{2}$ and the health professions ${ }^{3,4}$ goes under the name of vocational rehabilitation, the aim being to facilitate working for those who are willing and potentially able. The strategies can be described as top-down and bottom-up.

Top-down approaches to vocational rehabilitation relate to government policy, and were reviewed earlier this year by the Organization for Economic Co-operation and Development (OECD). ${ }^{5}$ The report outlines the strategies used by member states to meet two potentially conflicting goals - to enable people with disabilities to participate optimally in society (and particularly to engage in gainful employment) and at the same time to ensure that those unable to work have income security. So what can governments do? The report calls for recognition that the status of disability is independent of an individual's ability to work; that those with disabilities have obligations to society as well as the reverse; work/benefit packages; and that employers are crucial to this process.

An important driving force is the need to maximize the workforce, now shrinking in relation to the population of old or sick or disabled people requiring support. So governments are offering financial incentives to facilitate employment and trying to remove financial disincentives. The legislative approaches differ from country to country. In Austria, Denmark, Spain, Sweden and Switzerland a request for benefits is automatically treated as a request for vocational rehabilitation; in Germany, Norway and Poland, the degree of compulsion is slightly less; whilst in Australia, Canada, France, Italy, Korea, Mexico, Portugal, the UK and the USA vocational rehabilitation is entirely voluntary.

For health professionals, the vital message of the report concerns early intervention - the most effective measure against long-term ill health and consequent dependence on benefits. In this respect the strategy usually pursued in the UK, whereby the patient's possible return to work is considered only after completion of medical care, has come in for strong criticism. ${ }^{3}$ By contrast, Germany requires vocational rehabilitation to be part of the process before, during and after medical rehabilitation.

Increasing numbers in the UK are receiving incapacity benefits (now nearly 2.7 million) and efforts to halt or reverse the trend include strategies for minimizing work- 
induced injuries and illness; 6 NHS Plus as a potential occupational health scheme for the many workers not covered by such schemes; 'Pathways to Work' (based on recognition that unresolved health issues, in conjunction with other factors, create barriers to returning to work); $;^{2,7}$ and job retention and rehabilitation pilot schemes whereby health and employment agencies combine to help people with illness or injuries to continue with or return to work. ${ }^{2}$

What about bottom-up approaches? The OECD did not comment on differences in health provision but, according to one analysis, the escalation in disability benefits in the UK could be due to the decline of rehabilitation services. ${ }^{8}$ Rehabilitative approaches are bottom-up in that health professionals (particularly rehabilitation teams) work with employers, the local employment office and the voluntary sector to obtain a rapid reintegration of a person with a medical condition or disability into work., ${ }^{3,9}$ Though the OECD document recognizes that many with disabilities are able to work, it barely acknowledges the fact that people with long-term illness, who do not necessarily consider themselves disabled, commonly require vocational assistance to remain in employment. ${ }^{10}$ There is a window of opportunity: ${ }^{11,12}$ at first patients see themselves as 'sick' but with the prospect of returning to work; later they see themselves as 'disabled' and consequently unable to do so. ${ }^{13}$ The first phase is thought to last 2-4 months and is the time at which vocational rehabilitation is most likely to be effective through psychological and multidisciplinary management. ${ }^{13,14}$

What does bottom-up rehabilitation demand of health professionals? First, all must recognize a responsibility to assist ill or disabled people back into work where practicable $^{9,15}$ - a culture largely lacking in the NHS. ${ }^{3}$ Secondly, general practitioners and the primary health care team are pivotal 3,16,17 through their clinical management and their provision of sick notes which trigger or perpetuate absence from work. ${ }^{18}$ Good communication is crucialparticularly between general practitioners and occupational health physicians. ${ }^{18}$ Poor communication often results from a lack of clear rehabilitation goals from the outset. This in turn derives from the fact that, in many countries the world over, the management of work disability has not been viewed as an important part of medical practice outside the specialties of rehabilitation and occupational medicine. The Canadian Medical Association and the American College of Occupational and Environmental Medicine have both produced position statements setting out the physician's role in helping patients return to work. ${ }^{9}, 15$ In the UK a working group of the Society of Occupational Medicine, with other stakeholders, is proposing to draw up a similar statement. Employers, of course, carry great responsibility in these matters, ${ }^{19}$ especially by maintaining contact with their employee and supporting the rehabilitation strategies. ${ }^{9}$

In summary, top-down policies are important but cannot succeed without bottom-up efforts by health professionals and employers. All health professionals should seek to give positive advice about return to work before negative attitudes are formed. Where available, occupational health practitioners can give much assistance through job modification in arranging a phased return to work and support after return to work. ${ }^{20}$ In addition, both the British Society of Rehabilitation Medicine and the Royal College of Psychiatrists are calling for designated health professionals, 'vocational rehabilitation specialists', with the legal and practical knowledge to navigate the difficult waters between employment and health. ${ }^{3,17}$ Vocational rehabilitation is not merely of economic importance: it transforms lives.

Note AOF is a Medical Adviser for Kynixa Ltd. PS is a Principal Medical Adviser to the UK Department for Work and Pensions; the opinions expressed are personal.

\section{Andrew O Frank \\ Philip Sawney ${ }^{1}$}

British Society of Rehabilitation Medicine, Royal College of Physicians, Regent's Park, London NW1 4LE; 'Department for Work and Pensions, Room 638 Adelphi, 1-11 John Adam Street, London WC2N 6HT, UK

\section{REFERENCES}

1 Disability Rights Commission. Annual Review: Educating for Equality: Turning Ideas into Positive Action. Manchester: Disability Rights Commission, 2002

2 Department for Work and Pensions. Pathways to Work: Helping People into Employment. London: Department for Work \& Pensions, 2002

3 British Society of Rehabilitation Medicine. Vocational Rehabilitation: the Way Forward-Report of a Working Party (Chair, AO Frank). London: British Society of Rehabilitation Medicine, 2000

4 Carter T. Vocational rehabilitation. Occup Health Rev 2001; Sept/Oct:21

5 OECD. Transforming Disability into Ability: Policies to Promote Work and Income Security for Disabled People. Paris: OECD, 2003

6 Health \& Safety Commission and Health \& Safety Executive. Securing Health Together. London: Health \& Safety Executive, 2000

7 Department for Work and Pensions. Pathways to Work: Helping People into Employment - the Government's Response and Action Plan. London: Department for Work \& Pensions, 2003

8 Grahame R. The decline of rehabilitation services and its impact on disability benefits. J R Soc Med 2002;95:114-17

9 American College of Occupational and Environmental Medicine. The Attending Physician's Role in Helping Patients Return to Work after an Illness or Injury - a Consensus Opinion Statement. Illinois: American College of Occupational and Environmental Medicine, 2002

10 Frank AO, Chamberlain MA. Keeping our patients at work: implications for the management of rheumatoid arthritis and musculo-skeletal conditions. Rheumatology 2001;40:1201-5

11 Waldron HA. Sickness absence and rehabilitation: what hope of change? J R Soc Med 2001;94:105-6

12 Disler PB, Pallant JF. Vocational rehabilitation: everybody gains if injured workers are helped back into work. BMJ 2001;323:121-3 
13 Waddell G, Aylward M, Sawney P. Back Pain, Incapacity for Work and Social Security Benefits: an International Literature Review and Analysis. London: RSM Press, 2002

14 Main CJ, Spanswick C, Watson P. The nature of disability. In: Main CJ, Spanswick C, eds. Pain Management: an Interdisciplinary Approach. Edinburgh: Churchill Livingstone, 2003:89-106

15 CMA Policy Summary. The physician's role in helping patients return to work after an illness or injury. Can Med Assoc J 1997; 156: $680 \mathrm{~A}-\mathrm{C}$

16 Sawney P. Current issues in fitness for work certification. Br J Gen Pract 2002;52:217-22
17 Royal College of Psychiatrists. Employment Opportunities for People with Psychiatric Disability. A Report of the Royal College of Psychiatrists (Chair J Boardman) (CR 111). London: RCPsych, 2003

18 Beaumont D. Rehabilitation and retention in the workplace-the interaction between GPs and occupational health professionals. A consensus statement. Occup Med 2002;53: 254-5

19 Confederation of British Industry. Their Health in Your Hands: Focus on Occupational Health Partnerships. London: CBI, 2000

20 Mountain G, Carman S. Welfare to Work: an Overview of the Current and Potential Contributions of Occupational Therapy-Executive Summary and Bibliography. London: College of Occupational Therapists, 1999

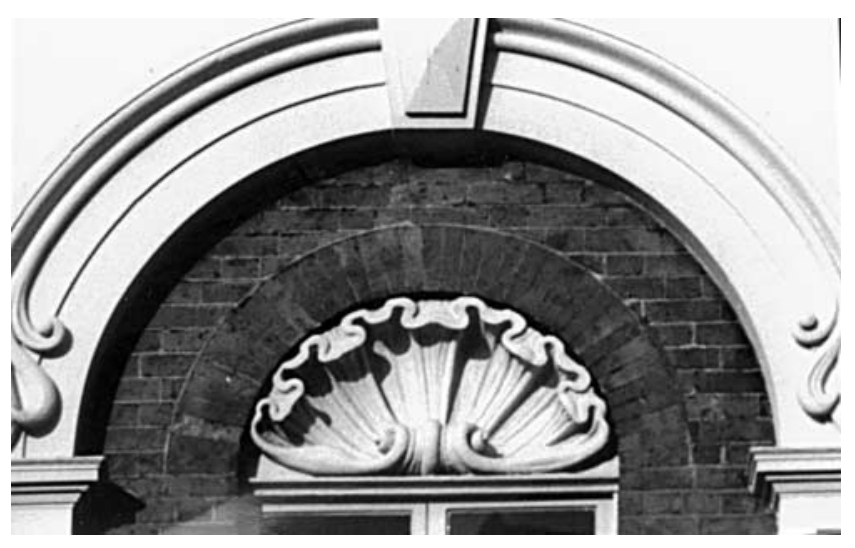

THE WORKHOUSE FOR THE CITY OF LONDON POOR LAW UNION: 'THE GRAND HOTEL'

In 1848 the Board of Governors of the City of London Union commissioned Richard Tress to design a large new workhouse for 1200 inmates, located outside the confines of the City on the south side of Bow Road. As befitted the status and wealth of the City, a flagship workhouse was planned. The size and architectural pretensions of the structure, built in a classical style, invited an ironic sobriquet; it was known in the East End as the Grand Hotel. During the past 150 years its use changed in line with altered patterns and priorities in local social and healthcare provision: the workhouse became an infirmary, then an institution and, in 1936, a psychiatric hospital, newly named St Clement's Hospital, Bow. Distinguished architectural features, including a decorative motif of large scallop shells, survived extensive damage and loss from bombing in the Second World War. Though scallop shells have been used as symbols of Christian pilgrimage since the 12th century, they have more commonly and non-specifically found favour as devices for architectural ornamentation in every period of classical revival.

Denis Gibbs 